\begin{tabular}{lc}
\hline \hline $\begin{array}{l}\text { MINING AND METALLURGY INSTITUTE BOR } \\
\text { UDK: 622 }\end{array}$ & $\begin{array}{l}\text { ISSN: 2334-8836 (Štampano izdanje) } \\
\text { ISSN: 2406-1395 (Online) }\end{array}$ \\
\hline \hline & \\
UDK: 669.35:536.7(045)=111 & doi:10.5937/MMEB1503123M \\
& Aleksandra Milosavljević ${ }^{*}$, Ana Kostov ${ }^{*}$
\end{tabular}

\title{
THERMODYNAMIC CALCULATIONS IN THE Cu-In-Sn SYSTEM ${ }^{* *}$
}

\begin{abstract}
Tin based alloys with addition of indium and copper are well discussed from the point of phase diagrams, but there are still properties which are not measured or calculated. Therefore, in this paper some calculations were performed in order to obtain the thermodynamic properties by prediction methods. The integral and partial molar excess Gibbs energies, as well as activities of tin in temperature range $873-1673 \mathrm{~K}$ were obtained for four sections In:Cu=1:1, 1:4, 4:1 and 9:1 in the Cu-In-Sn system.
\end{abstract}

Keywords: thermodynamic properties, prediction methods, copper, indium, tin.

\section{INTRODUCTION}

Although the $\mathrm{Cu}-\mathrm{In}-\mathrm{Sn}$ system has been studied a lot and there are the phase diagrams which have been calculated [1-6], there always is a need for more investigations and calculations in order to expand the existing data.

Phase equilibria for the system $\mathrm{Cu}-\mathrm{In}-\mathrm{Sn}$ was investigated by Liu et al. [6], who used the experimental results (differential scanning calorimetry and optical microscopy) and optimized values for binary systems. The liquidus projection for the $\mathrm{Cu}-\mathrm{In}$-Sn system and 8 isotermal sections at $110-900^{\circ} \mathrm{C}$ were given by them [6]. Contribution to the phase equilibria in this ternary system was also given by Milosavljević et al. [7], who determined the phase diagram of section with $\mathrm{Cu}: \mathrm{In}=1: 9$ in the $\mathrm{Sn}-\mathrm{In}-\mathrm{Cu}$ ternary system, based on thermal analysis and scanning electron microscopy with the energy dispersive X-ray data and applied calcula tion of phase diagrams method (CALP$\mathrm{HAD})$.

A. T. Dinsdale and A. Watson systematized the results obtained for various solder systems in the atlas of phase diagrams [8], and the $\mathrm{Cu}-\mathrm{In}-\mathrm{Sn}$ as one as potential of ecological solder systems is among them, too. The thermodynamic prediction of the $\mathrm{Cu}$-In$\mathrm{Sn}$ system is performed based on parameters for constitutive binary systems which are included in large COST531 database [9].

\section{THEORETICAL FUNDAMENTALS}

Knowledge of the thermodynamic properties of a system has practical and scientific significance. On the basis of thermodynamic values, behaviour of components can be defined in the test system. Due to these reasons, in order to predict the thermodynamic properties of multicomponent system, the

\footnotetext{
* Mining and Metallurgy Institute Bor, Zeleni bulevar 35, 19210 Bor, Serbia e-mail:aleksandra.milosavljevic@irmbor.co.rs

** The research presented in this paper has been done in the frame of the projects: "Development of Ecological Knowledge-Based Advanced Materials and Technologies for Multifunctional Application" No. 34005 financed by the Ministry of Education, Science and Technological Development of the Republic of Serbia
} 
mathematical models were developed based on the characteristics of the elements or components of the system. Also, the adequacy of the applied mathematical models is possible to determine by comparative analysis of the calculated values, with no experimental measurements to test the system.

Basic mathematical interpretation of these models is based on the Gibbs energy for the multicomponent system calculated in dependence of the Gibbs energy of the bi nary system. In this way, at any point in the isothermal section of the multicom-ponent system an excess of the integral molar Gibbs energy can be determined using values of integral molar excess Gibbs energy for constitutive binary systems. There are usually two kinds of models which are popular for description of ternary systems. These are geometrical models symmetric [10] and asymmetric [11] models.

The basic equations of these predicting models are given as follows:

Toop model:

$$
\begin{aligned}
\Delta G_{123}^{x s} & =\frac{X_{2}}{1-X_{1}} \Delta G_{12}^{x s} X_{1} ; 1-X_{1}+\frac{X_{3}}{1-X_{1}} \Delta G_{13}^{x s} \quad X_{1} ; 1-X_{1} \\
& +X_{2}+X_{3}{ }^{2} \Delta G_{23}^{x s}\left(\frac{X_{2}}{X_{2}+X_{3}} ; \frac{X_{3}}{X_{2}+X_{3}}\right)
\end{aligned}
$$

Kohler model:

$$
\begin{aligned}
\Delta G_{123}^{x s} & =X_{1}+X_{2}{ }^{2} \Delta G_{12}^{x s}\left(\frac{X_{1}}{X_{1}+X_{2}} ; \frac{X_{2}}{X_{1}+X_{2}}\right)+X_{2}+X_{3}^{2} \Delta G_{12}^{x s}\left(\frac{X_{2}}{X_{2}+X_{3}} ; \frac{X_{3}}{X_{2}+X_{3}}\right) \\
& +X_{3}+X_{1}{ }^{2} \Delta G_{12}^{x s}\left(\frac{X_{3}}{X_{1}+X_{3}} ; \frac{X_{1}}{X_{1}+X_{3}}\right)
\end{aligned}
$$

In both equations corresponds to the integral molar excess Gibbs energy for ternary system, while $\mathrm{X}_{1}, \mathrm{X}_{2}, \mathrm{X}_{3}$ correspond to the mole fraction of components in investigated system. Integral molar excess Gibbs energies for constitutive binary systems, $\Delta G_{i j}^{X S}(\mathrm{i}, \mathrm{j}=1,2,3)$ are obtained using Redlich-Kister parameters from COST531 Database [9].

\section{RESULTS AND DISCUSSION}

In this paper, the thermodynamic properties for the ternary $\mathrm{Cu}-\mathrm{In}$-Sn system are calculated for the sections with constant molar ratio $\mathrm{In}: \mathrm{Cu}=1: 1,1: 4,4: 1$ and $9: 1$ at $873 \mathrm{~K}$ up to $1673 \mathrm{~K}$ and by different models Kohler [10] [11].

In order to present all calculated values for integral and partial molar excess of the Gibbs energies, as well as activities of tin, the results of this thermodynamic properties are given in form of diagrams in Figures 1-3 for the Kohler method, and Figures 4-6 for the Toop method. Basic data for the thermodynamic calculation were the values of integral molar excess Gibbs energies for constitutive binary systems $\Delta G_{i j}^{X S}$, which are calculated using the Redlich-Kister parameters from COST531 database [9]. These calculated values are given in Tables $1-3$. 
The R-K parameters for the constitutive binary systems are:

- System In-Sn:

PARAMETER G(LIQUID,IN,SN;0) 298.15 -828.54+0.76018*T-0.1211767*T*LOG(T); $3000 \mathrm{~N}$ !

PARAMETER G(LIQUID,IN,SN;1) 298.15 -115.59-1.39997*T; 3000 N !

- System In-Cu:

PARAMETER G(LIQUID,CU,IN;0) $298.15-41564.79+238.616 * T-29.827 * T * L N(T)$; $6000.00 \mathrm{~N}$ !

PARAMETER G(LIQUID,CU,IN;1) 298.15 -76057.785+371.306*T-44.944*T*LN(T); $6000.00 \mathrm{~N}$ !

PARAMETER G(LIQUID,CU,IN;2) 298.15 -42076.516+192.395*T-23.281*T*LN(T); $6000.00 \mathrm{~N}$ !

- System Sn-Cu:

\$PARAMETER G(LIQUID,CU,SN;0) 298.15 -9002.8-5.8381*T; $3000 \mathrm{~N}$ ! \$PARAMETER G(LIQUID,CU,SN;1) 298.15 -20100.4+3.6366*T; $3000 \mathrm{~N}$ ! \$PARAMETER G(LIQUID,CU,SN;2) 298.15 -10528.4; 3000 N !

Table 1 Calculated values for , J/mol using the Redlich-Kister parameters [9]

\begin{tabular}{|c|c|c|c|c|c|c|c|c|c|c|}
\hline \multicolumn{2}{|c|}{ Alloy } & \multicolumn{10}{c|}{$\Delta G_{I n-S n}^{x s}$, J/mol } \\
\hline $\mathbf{X}_{\text {In }}$ & $\mathbf{X}_{\text {Sn }}$ & $\mathbf{8 7 3 K}$ & $\mathbf{9 7 3 K}$ & $\mathbf{1 0 7 3 K}$ & $\mathbf{1 1 7 3 K}$ & $\mathbf{1 2 7 3 K}$ & $\mathbf{1 3 7 3 K}$ & $\mathbf{1 4 7 3 K}$ & $\mathbf{1 5 7 3 K}$ & $\mathbf{1 6 7 3 K}$ \\
\hline 1 & 0 & 0 & 0 & 0 & 0 & 0 & 0 & 0 & 0 & 0 \\
\hline 0.9 & 0.1 & 53 & 67 & 80 & 93 & 106 & 119 & 132 & 145 & 158 \\
\hline 0.8 & 0.2 & 52 & 71 & 90 & 109 & 128 & 146 & 165 & 184 & 202 \\
\hline 0.7 & 0.3 & 12 & 31 & 50 & 69 & 88 & 107 & 125 & 144 & 162 \\
\hline 0.6 & 0.4 & -50 & -35 & -20 & -5 & 9 & 24 & 39 & 53 & 67 \\
\hline 0.5 & 0.5 & -119 & -110 & -102 & -93 & -85 & -77 & -68 & -60 & -52 \\
\hline 0.4 & 0.6 & -178 & -177 & -175 & -174 & -173 & -171 & -170 & -169 & -168 \\
\hline 0.3 & 0.7 & -212 & -217 & -221 & -226 & -231 & -236 & -240 & -245 & -251 \\
\hline 0.2 & 0.8 & -204 & -212 & -220 & -228 & -236 & -245 & -253 & -261 & -269 \\
\hline 0.1 & 0.9 & -139 & -146 & -153 & -160 & -167 & -174 & -181 & -189 & -196 \\
\hline 0 & 1 & 0 & 0 & 0 & 0 & 0 & 0 & 0 & 0 & 0 \\
\hline
\end{tabular}

Table 2 Calculated values for

, J/mol using the Redlich-Kister parameters [9]

\begin{tabular}{|c|c|c|c|c|c|c|c|c|c|c|}
\hline \multicolumn{2}{|c|}{ Alloy } & \multicolumn{10}{|c|}{, $\mathbf{J} / \mathbf{m o l}$} \\
\hline $\mathbf{X}_{\text {In }}$ & $\mathbf{X}_{\mathbf{C u}}$ & $\mathbf{8 7 3 K}$ & $\mathbf{9 7 3 K}$ & $\mathbf{1 0 7 3 K}$ & $\mathbf{1 1 7 3 K}$ & $\mathbf{1 2 7 3 K}$ & $\mathbf{1 3 7 3 K}$ & $\mathbf{1 4 7 3 K}$ & $\mathbf{1 5 7 3 K}$ & $\mathbf{1 6 7 3 K}$ \\
\hline 0 & 1 & 0 & 0 & 0 & 0 & 0 & 0 & 0 & 0 & 0 \\
\hline 0.1 & 0.9 & -272 & -307 & -351 & -402 & -460 & -524 & -593 & -669 & -749 \\
\hline 0.2 & 0.8 & -520 & -566 & -631 & -713 & -810 & -921 & -1045 & -1182 & -1330 \\
\hline 0.3 & 0.7 & -929 & -950 & -1005 & -1091 & -1205 & -1344 & -1507 & -1693 & -1899 \\
\hline 0.4 & 0.6 & -1568 & -1528 & -1542 & -1605 & -1713 & -1861 & -2048 & -2270 & -2525 \\
\hline 0.5 & 0.5 & -2397 & -2268 & -2216 & -2233 & -2314 & -2454 & -2648 & -2893 & -3185 \\
\hline 0.6 & 0.4 & -3259 & -3032 & -2903 & -2863 & -2904 & -3021 & -3207 & -3458 & -3769 \\
\hline 0.7 & 0.3 & -3887 & -3581 & -3386 & -3292 & -3290 & -3374 & -3536 & -3772 & -4077 \\
\hline 0.8 & 0.2 & -3901 & -3573 & -3352 & -3228 & -3193 & -3240 & -3364 & -3558 & -3818 \\
\hline 0.9 & 0.1 & -2808 & -2562 & -2391 & -2288 & -2247 & -2263 & -2332 & -2451 & -2615 \\
\hline 1 & 0 & 0 & 0 & 0 & 0 & 0 & 0 & 0 & 0 & 0 \\
\hline
\end{tabular}


Table 3 Calculated values for , J/mol using the Redlich-Kister parameters [9]

\begin{tabular}{|c|c|c|c|c|c|c|c|c|c|c|}
\hline \multicolumn{2}{|c|}{ Alloy } & \multicolumn{10}{c|}{, $\mathbf{J} / \mathbf{m o l}$} \\
\hline $\mathbf{X}_{\mathbf{S n}}$ & $\mathbf{X}_{\mathbf{C u}}$ & $\mathbf{8 7 3 K}$ & $\mathbf{9 7 3 K}$ & $\mathbf{1 0 7 3 K}$ & $\mathbf{1 1 7 3 K}$ & $\mathbf{1 2 7 3 K}$ & $\mathbf{1 3 7 3 K}$ & $\mathbf{1 4 7 3 K}$ & $\mathbf{1 5 7 3 K}$ & $\mathbf{1 6 7 3 K}$ \\
\hline 0 & 1 & 0 & 0 & 0 & 0 & 0 & 0 & 0 & 0 & 0 \\
\hline 0.1 & 0.9 & -657 & -735 & -846 & -893 & -972 & -1050 & -1129 & -1208 & -1286 \\
\hline 0.2 & 0.8 & -1237 & -1366 & -1552 & -1622 & -1751 & -1879 & -2007 & -2136 & -2264 \\
\hline 0.3 & 0.7 & -1893 & -2046 & -2275 & -2352 & -2505 & -2659 & -2812 & -2965 & -3118 \\
\hline 0.4 & 0.6 & -2672 & -2830 & -3074 & -3145 & -3303 & -3460 & -3618 & -3775 & -3933 \\
\hline 0.5 & 0.5 & -3525 & -3671 & -3907 & -3963 & -4109 & -4255 & -4400 & -4546 & -4692 \\
\hline 0.6 & 0.4 & -4297 & -4420 & -4629 & -4665 & -4788 & -4911 & -5033 & -5156 & -5279 \\
\hline 0.7 & 0.3 & -4736 & -4828 & -4996 & -5012 & -5105 & -5197 & -5289 & -5381 & -5473 \\
\hline 0.8 & 0.2 & -4487 & -4546 & -4662 & -4663 & -4721 & -4780 & -4838 & -4897 & -4955 \\
\hline 0.9 & 0.1 & -3094 & -3120 & -3179 & -3173 & -3199 & -3226 & -3252 & -3278 & -3305 \\
\hline 1 & 0 & 0 & 0 & 0 & 0 & 0 & 0 & 0 & 0 & 0 \\
\hline
\end{tabular}

\section{Kohler method}

Figure 1 shows the dependence of integral molar Gibbs energy for $\mathrm{Cu}-\mathrm{In}-\mathrm{Sn}$ system for all sections, and at $873 \mathrm{~K}$ as well as $1673 \mathrm{~K}$. It should be noted that the increase of temperature does not significantly affect the excess Gibbs energy dependence of composition.

Tin activities for all examined temperatures and almost all the sections are

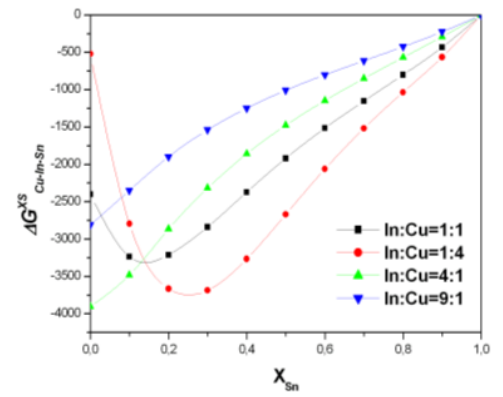

a) $873 K$ very close to the Raoult's line. The exceptions are sections with molar ratio of $\mathrm{In}: \mathrm{Cu}=1: 1$ and $1: 4$, where the negative deviation is observed for the compositions to $\mathrm{X}_{\mathrm{Sn}}<0.4$ (Figure 3). Alloys with higher content of indium, as in section In: $\mathrm{Cu}=9: 1$ showed the less deviation from the ideal solution.

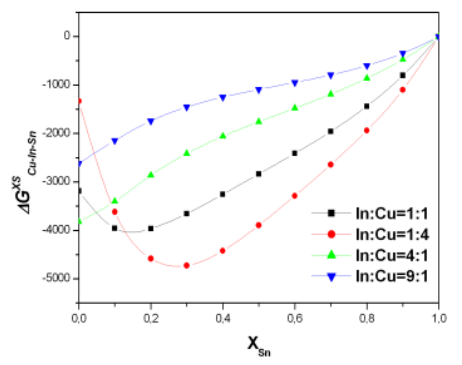

b) $1673 \mathrm{~K}$

Figure 1 Calculated values for $\Delta G_{C u-I n-S n}^{x s}$ in the Cu-In-Sn system by the Kohler method

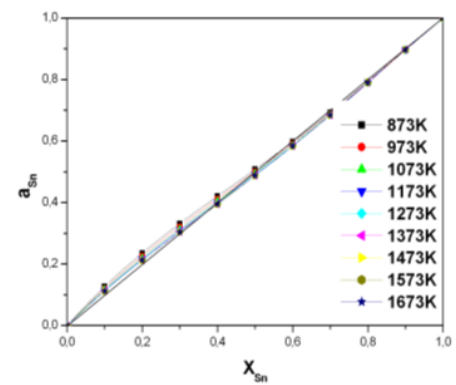

Figure 2 Tin activity in the $\mathrm{Cu}-\mathrm{In}$-Sn system (In:Cu=9:1) at various temperature by the Kohler method 


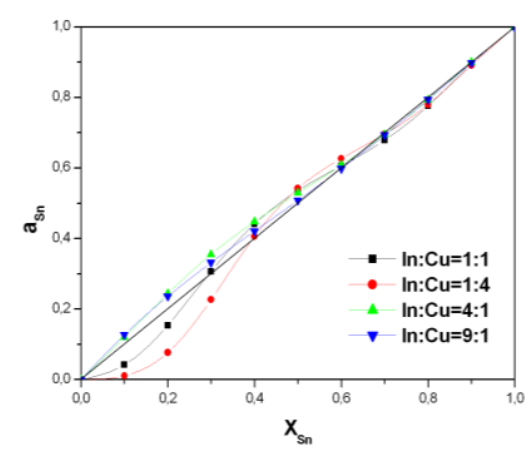

a) $873 \mathrm{~K}$

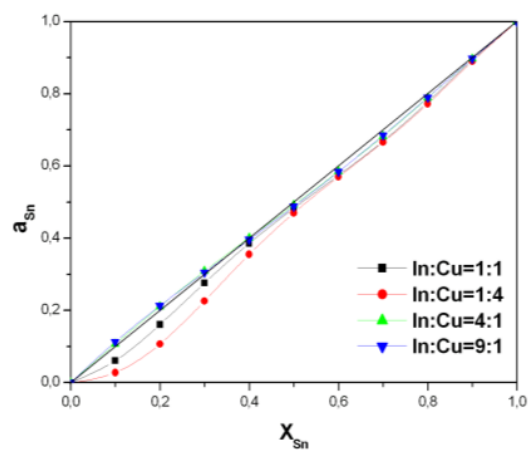

b) $1673 \mathrm{~K}$

Figure 3 Tin activity in the Cu-In-Sn system for various molar ratio In:Cu by the Kohler method

\section{Toop method}

The results of Toop model application pointed out that the values for tin activity are almost identical in the sections with higher concentrations of indium, depending on temperature. By increase the con-

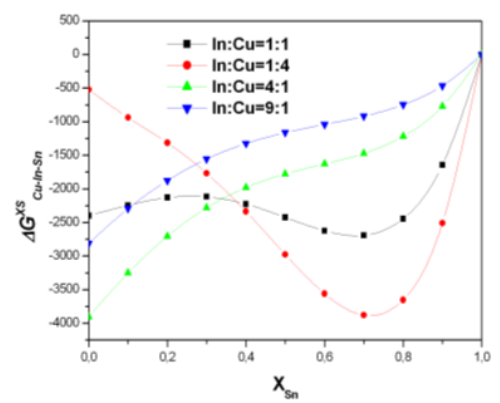

a) $873 \mathrm{~K}$ tent of indium, tin activity values are close to the Raoult's line (Figure 5), while the alloys in section $\mathrm{In}: \mathrm{Cu}=1: 4$ have the largest negative deviation at all temperatures (Figure 6).

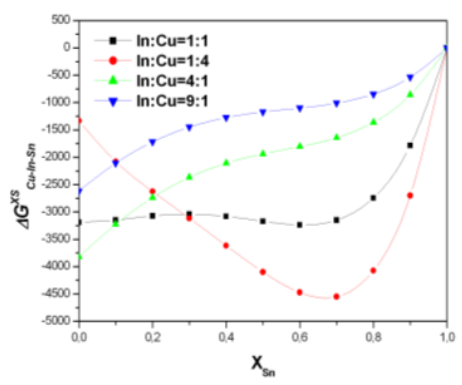

b) $1673 \mathrm{~K}$

Figure 4 Calculated values for $\Delta G_{C u-I n-S n}^{x s}$ in the Cu-In-Sn system by the Toop method

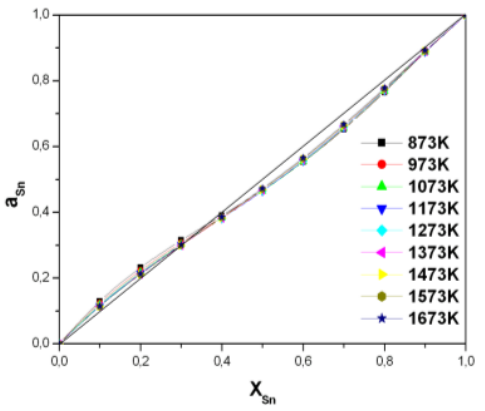

Figure 5 Tin activity in the $\mathrm{Cu}-\mathrm{In}$-Sn system (In:Cu=9:1) at various temperature by the Toop method 


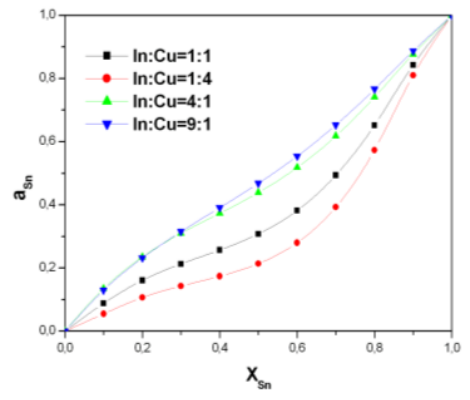

a) $873 \mathrm{~K}$

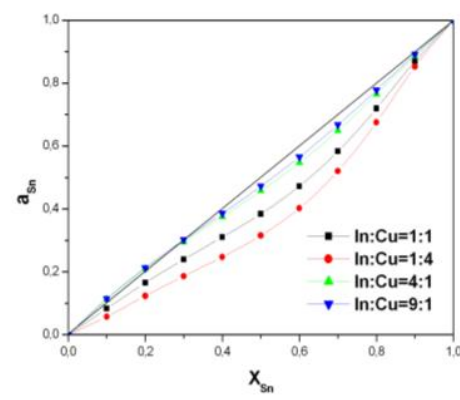

b) $1673 \mathrm{~K}$

Figure 6 Tin activity in the Cu-In-Sn system for various molar ratio In:Cu by the Toop method

Both models show good results, so that is a question which one better describe those $\mathrm{Cu}-\mathrm{In}$-Sn alloys. Considering the fact that Popović et al. [12] experimentally obtained indium activity in this system at $1173 \mathrm{~K}$, and the calculated values for the same are obtained by Milosavljević [13], it seems to be that the best agreement shows the Kohler method. Calculated values for indium activity by the Toop model [13] showed absolutely disagreement with experimentally obtained activities for the $\mathrm{Cu}-\mathrm{In}$-Sn alloys [12]. Therefore, it can be confirmed that the better one is symmetric type of predicted model.

\section{CONCLUSIONS}

The results of thermodynamic prediction presented in this paper included values of thermodynamic properties which are calculated using by geometric solution models in wide temperature range from 873 up to $1673 \mathrm{~K}$. Therefore the Kohler and Toop models were used in order to obtained integral and partial molar excess of the Gibbs energies and tin activities for investigated sections in $\mathrm{Cu}-\mathrm{In}$-Sn system.

As a potential candidate for ecological solder alloy, the $\mathrm{Cu}-\mathrm{In}-\mathrm{Sn}$ system needs to be well investigated, so these calculated thermodynamic quantities of chosen alloys enabling better understanding and expansion of existing database for this kind of alloys. The application of symmetric models for thermodynamic prediction is confirmed with calculations as well as experimentally.

\section{REFERENCES}

[1] Korhonen T.M., Kivilahti J.K., JEM, 27(1998)149

[2] Ohnuma I., Cui Y., Liu X.J., et al., JEM, 29(2000)1113

[3] Liu X. J., Inohana Y., Takaku Y., Ohnuma I., al., JEM, 31(2002)1139

[4] Moser Z., Gasior W., Pstrus J., et al., JEM, 30(2001)1120

[5] S. K. Lin, C. F. Yang, S. H. Wu, S. W. Chen, JEM, 37 (2008) 498

[6] X. J. Liu, H. S. Liu, I. Ohnuma, et. al., JEM, 30 (2001) 1093

[7] Milosavljević A., Živković D., Manasijević D., Talijan N., Ćosović V., Grujić A. International Journal Materials and Product Technology 39 (1-2) (2010) 95.

[8] A.T. Dinsdale, A. Watson, A. Kroupa, J. Vrestal, A. Zemanova, J. Vizdal, Cost Action 531-Atlas of Phase Diagrams for Lead-free Soldering, 2008.

[9] http://resource.npl.co.uk/mtdata/ cost531.htm

[10] Kohler F., Monatsh. Chem. 91(1960) 738

[11] Toop G.W., Trans. Met. Soc. AIME 233(1965)850

[12] Popović A., Bencze L., International Journal of Mass Spectrometry 257 (2006) 41

[13] Milosavljević A., Doctoral Dissertation, Bor, 2010 